\title{
Renal tubular dysgenesis with hypocalvaria and ileocecal valve agenesis: an autopsy report
}

\author{
Ariel Barreto Nogueira ${ }^{a}$, Regina Schultz ${ }^{a}$, Adolfo Wenjaw Liao ${ }^{b}$, \\ Rossana Pulcineli Vieira Fancisco ${ }^{b}$, Marcelo Zugaib ${ }^{b}$
}

Nogueira AB, Schultz R, Liao AW, Francisco RPV, Zugaib M. Renal tubular dysgenesis with hypocalvaria and ileocecal valve agenesis: an autopsy report. Autopsy Case Rep [Internet]. 2012;2(4):27-33. http://dx.doi.org/10.4322/acr.2012.031

\section{ABSTRACT}

Renal tubular dysgenesis (RTD) is a rare, lethal, autosomal recessive disorder characterized by non-differentiation of the renal proximal convoluted tubules, resulting in oligohydramnios. It is usually diagnosed in the second trimester of pregnancy, following the oligohydramnios sequence, pulmonary hypoplasia and hypocalvaria. The prognosis is poor, and death usually occurs in utero or within the first few days of life. The pathogenesis of RTD is associated with the perinatal use of drugs, such as angiotensin- converting enzyme inhibitors, angiotensin II receptor antagonists, and anti- inflammatory drugs, as well as with fetal transfusion syndrome, genetic mutations in the pathway of the renin-angiotensin system pathway, cocaine snorting, or other pathological mechanisms that reduce renal blood flow. Here, we report the autopsy of a neonate born to consanguineous parents at 38 weeks of gestation, with RTD, decreased amniotic fluid, oligohydramnios sequence, hypocalvaria, pulmonary hypoplasia, and ileocecal valve agenesis. To our knowledge, the latter has never been reported associated with RTD.

Keywords: Urogenital abnormalities; Craniofacial abnormalities; lleocecal valve; Autopsy; Oligohydramnios.

\section{CLINICAL CASE}

We report the case of a 20 -year-old woman who was pregnant for the second time and who had previously had a vaginal delivery. She reported no alcohol consumption, smoking, illegal drug use, or use of medications other than those that are typically used during pregnancy. Prenatal serology was negative for HIV, syphilis, hepatitis $B$, and hepatitis $\mathrm{C}$, as well as revealing immunity to toxoplasmosis and rubella.
She gave birth to a male infant (gestational age, 38 weeks) via an assisted vaginal delivery for breech presentation. The infant presented with apnea and hypotonia at birth. The one-minute, five-minute, and ten-minute Apgar scores were 1 , 4 , and 4, respectively. Birth weight was $2,120 \mathrm{~g}$. After neonatal resuscitation, the infant started on mechanical ventilation and vasoactive drugs and was referred to the intensive care unit, having

\footnotetext{
${ }^{a}$ Department of Pathology - Hospital das Clínicas - Faculdade de Medicina - Universidade de São Paulo, São Paulo/SP - Brazil.

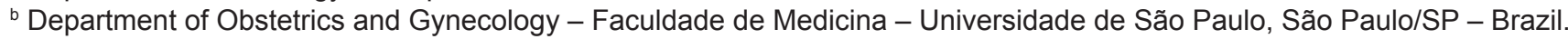

Copyright $\odot 2012$ Autopsy and Case Reports - This is an Open Access article distributed of terms of the Creative Commons Attribution NonCommercial License (http://creativecommons.org/licenses/by/3.0/) which permits unrestricted non-commercial use, distribution, and reproduction in any médium provided article is properly cited.
} 
remained anuric for the duration of his stay. Intensive supportive measures were ineffective, and the infant died at 9 hours after delivery. An autopsy was performed, the legal guardians having given written informed consent. The parents were consanguineous (first cousins).

\section{AUTOPSY FINDINGS}

Macroscopic examination revealed the presence of the oligohydramnios sequence, also known as Potter's Sequence, i.e., retrognathism, a flattened nose, knee hyperflexion, ulnar deviation, and flat, clubbed feet (Figure 1), as well as the presence of amnion nodosum on the placenta. Head circumference was $31 \mathrm{~cm}$ (reference range for the gestational age, $32-36.5 \mathrm{~cm}$ ). The anterior fontanelle was wide and bulging. The calvarial bones were thin, a finding that was consistent with hypocalvaria. Kidneys were topic with fetal lobulation, an intact corticomedullary junction, a combined kidney weight of $19.7 \mathrm{~g}$ (normal weight, $24.8 \pm 7.2 \mathrm{~g}$ ), and an intact pyelocaliceal system. Other findings included agenesis of the ileocecal valve, which was characterized by the absence of the ileocecal junction, dilated small bowel loops (up to $2 \mathrm{~cm}$ in diameter), and short, hypoplastic colon (up to $0.6 \mathrm{~cm}$ in diameter). The small intestinal contents were thick and greenish. The contents of the colonic lumen were mucous and whitish. There were diffuse adhesions in the abdominal cavity. In addition, the abdominal organs had a greenish, finely granular outer surface. We found no intestinal perforation. The lungs were hypoplastic and, together, weighed $20 \mathrm{~g}$ (normal lung weight for the gestational age, $40.6 \pm 17.1 \mathrm{~g}$ ), and the lung weight to body weight ratio was 0.009 (normal ratio, $>0.012$ ). The heart showed interatrial communication (patent foramen ovale).

Histological examination revealed kidneys with diffusely distributed glomeruli in the renal parenchyma, including the renal papilla. The renal tubules consisted of cuboidal cells with clear nuclei and scant basophilic cytoplasm (Figure 2A-C). Periodic acid-Schiff staining revealed a lack of proximal tubules, the brush border membrane, typical of these structures, having remained unstained (Figure 2D)..$^{1,2,3}$ Immunohistochemistry with the markers of proximal tubular differentiation, i.e., anti-CD10 antibodies (Figure 3A) and antiCD15 antibodies (Figure 3B), also showed proximal tubular hypoplasia. ${ }^{4,5} \mathrm{Imm}$ unohistochemical staining was diffusely positive for epithelial membrane antigen, which is characteristic of distal tubules (Figure 3C). ${ }^{1-4,6}$ The renal arteries were tortuous and had thickened walls (Figure 3D), findings that constituted further evidence of RTD. ${ }^{4-6}$ As a
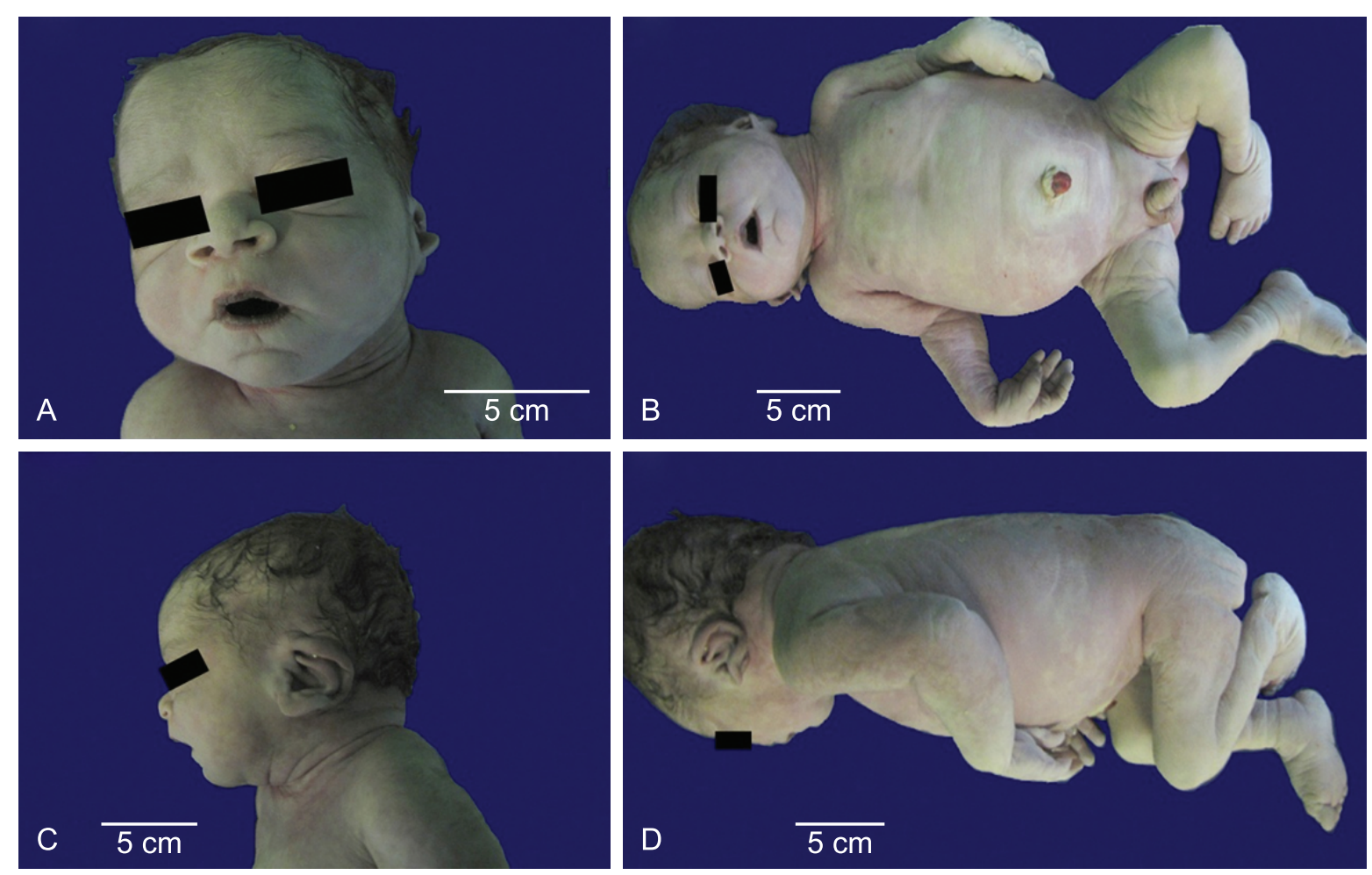

Figure 1 - The oligohydramnios sequence: A - Wide and bulging fontanelle; B - Knee hyperflexion and ulnar deviation; C - Retrognathism; D - Knee hyperflexion. 

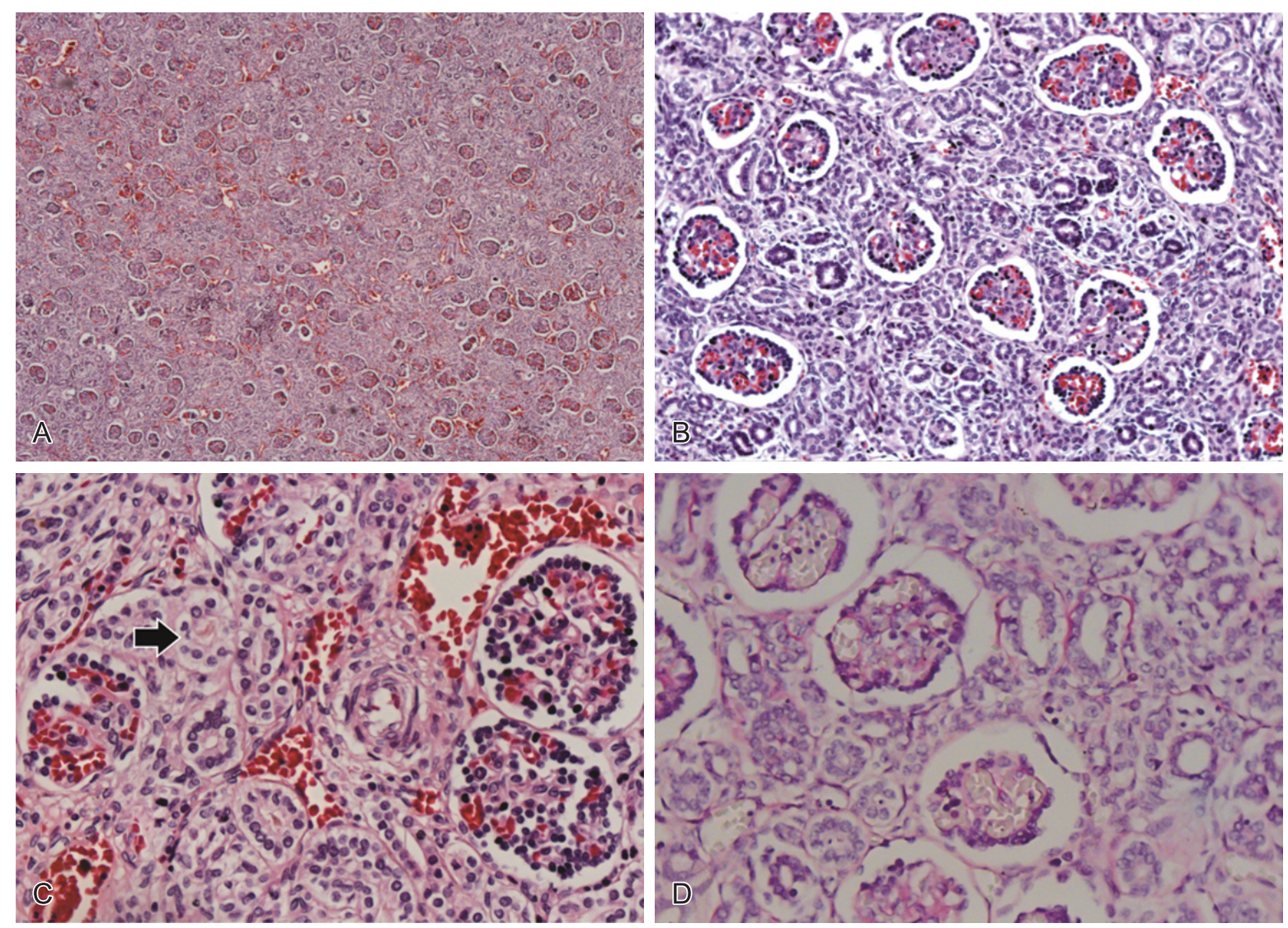

Figure 2 - Photomicrography of the kidney - Renal tubular dysgenesis: A - Diffusely distributed glomeruli in the renal parenchyma (hematoxylin and eosin [H\&E]; magnification, $\times 50$ ); B - Diffusely distributed distal tubules (H\&E; magnification, $\times 200$ ); C - Distal tubules with cuboidal cells with clear cytoplasm (arrow) and thick-walled vessels (H\&E; magnification, $\times 400$ ); D - Histochemical analysis showing that the brush border membrane, which is characteristic of proximal tubules, remained unstained (periodic acid-Schiff staining; magnification, $\times 400)$.

control, we used a kidney sample from a neonate (gestational age, 39 weeks and 2 days) who had normal kidney development and whose cause of death was unrelated to the genitourinary tract (Figure 4).

We found pulmonary hypoplasia secondary to oligohydramnios and RTD. In addition to our finding of decreased lung weight, we found that the alveoli were collapsed and reduced in number; bronchiolar structures were proportionally large and tortuous in the lung periphery, being accompanied by large vessels (Figure $5 \mathrm{~A}$ and $5 \mathrm{~B}$ ). We found hyaline membrane formation within foci of enlarged alveoli (Figure 5B).

Ileocecal valve agenesis was confirmed by microscopic examination, which revealed, absence of valvar lumen. The ileum and cecum showed two joined layers of muscularis propria and no adjacent serosa. The intestinal crypts were malformed, dilated, and tortuous, sometimes showing basal branching (Figure 5C).
We found meconium peritonitis secondary to the ileocecal valve agenesis and probable intestinal perforation, a finding that has been reported in some cases of RTD..$^{1,4}$ In the diaphragm and in the gastric and intestinal subserosas, we found lymphomononuclear inflammatory infiltrate, macrophages with greenish cytoplasmic granules, and vernix squames, some of which were calcified (Figure 5D). The presence of periventricular leukomalacia constituted further evidence of fetal distress.

\section{DISCUSSION}

A rare disorder, RTD is characterized by oligohydramnios - usually diagnosed in the second trimester of pregnancy $(20-23 \text { weeks })^{4,7}$ - progressing to the oligohydramnios sequence, pulmonary hypoplasia, ${ }^{1,3,5,8,9}$ and early death, either in utero or within a few days after birth. ${ }^{2,4,7,9}$ There are only a few reports of survival past the neonatal period. ${ }^{5,10,11}$ 

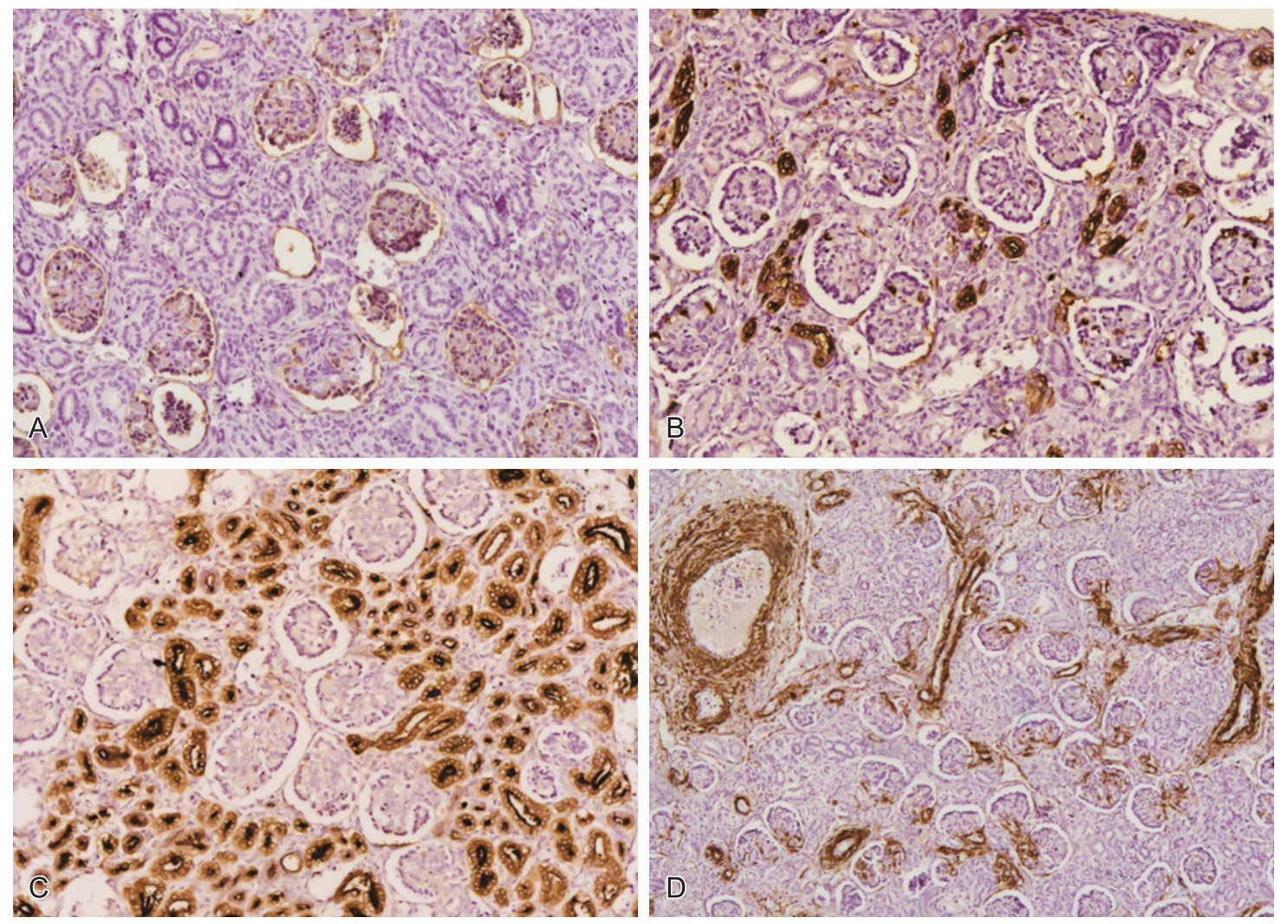

Figure 3 - Photomicrography of the kidney - Renal tubular dysgenesis, immunohistochemistry: A - with antiCD10 antibodies and B - with anti-CD15 antibodies, both showing a lack of proximal tubule differentiation (magnification, $\times 200$ ); C - Diffuse staining for epithelial membrane antigen, characteristic of distal tubules (magnification, $\times 200$ ); $\mathbf{D}$ - for smooth muscle actin, showing tortuous, thick-walled vessels (magnification, $\times 200$ ).
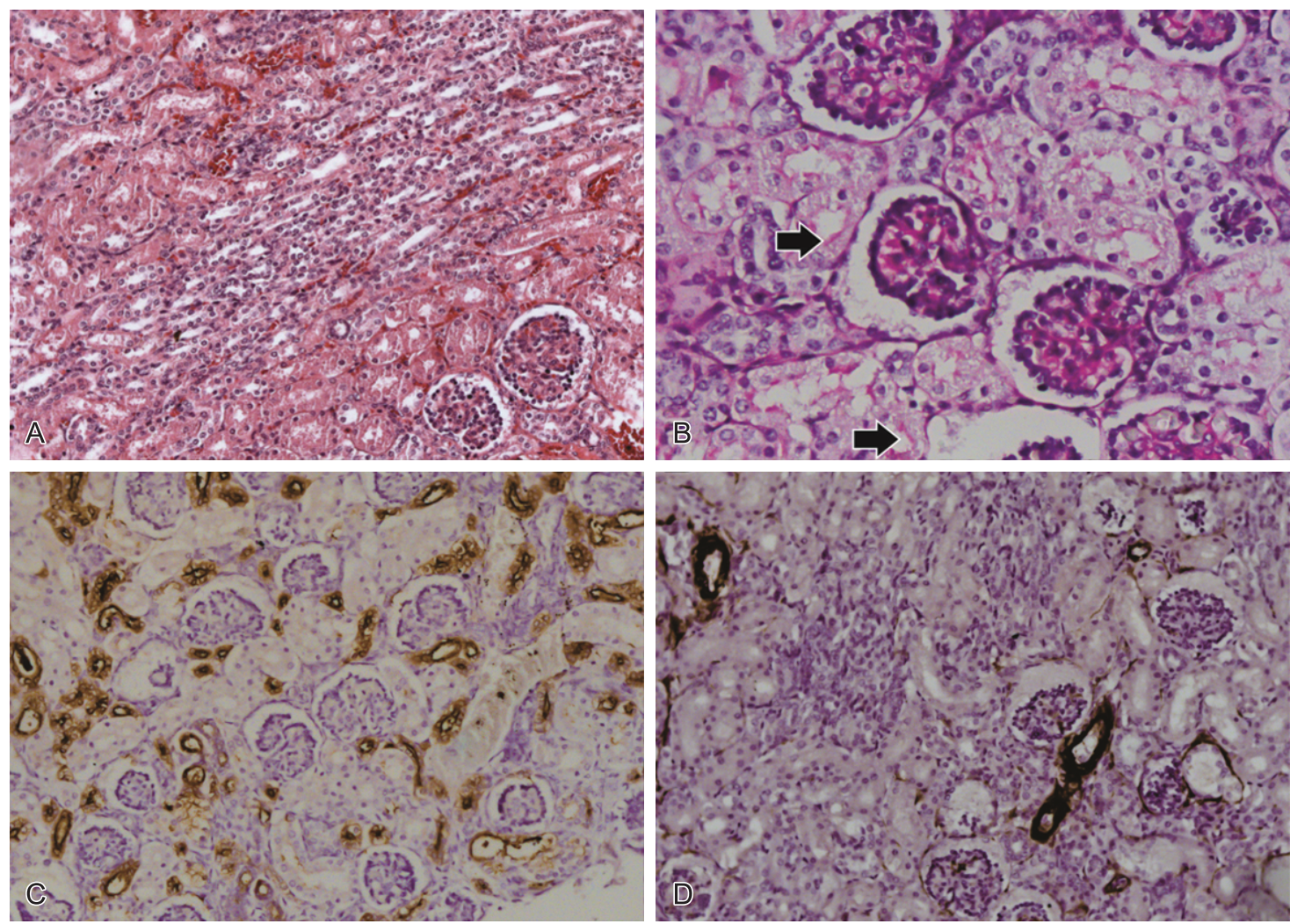

Figure 4 - Photomicrography of the control kidney. A - Proximal tubule differentiation, rich in acidophilic cells (hematoxylin and eosin; magnification, $\times 200$ ); B - Stained brush border membrane in proximal tubules (arrow; periodic acid-Schiff staining; magnification, $\times 400$ ); C - Positivity for epithelial membrane antigen, the proximal tubules remaining unstained (immunohistochemistry; magnification, $\times 200$ ); D - Immunohistochemistry for smooth muscle actin (magnification, $\times 200$ ). 



Figure 5 - Photomicrography of the lung. A - Pulmonary hypoplasia (H\&E, magnification $\times 50)$; B - Collapsed alveoli and hyaline membrane formation (arrow) (H\&E, magnification $\times 400$ ); $\mathbf{C}-$ photomicrography of the ileocecal region showing agenesis of the ileocecal valve $(\mathrm{H} \& \mathrm{E}$, magnification $\times 50)$; $\mathbf{D}$ - photomicrography of the peritoneum and diaphragm muscle showing meconium peritonitis, note macrophages with brownish granules (arrowhead) and calcification (asterisk) amid lymphomononuclear inflammatory infiltrate (H\&E, $\times 400$ )

Prolonged exposure to certain medications or illicit drugs, such as cocaine, can lead to decreased renal blood flow and hyperactivation of the reninangiotensin system (RAS), therefore leading to RTD. A similar mechanism explains RTD in cases of twin-to-twin transfusion syndrome. ${ }^{4}$ Recent studies have demonstrated numerous autosomal recessive mutations in RAS- related genes leading to RTD. ${ }^{4,5,7,11,12}$ Consanguinity is identified in $12 \%$ to $32 \%$ of cases. $^{1,4,5}$

The RAS controls extracellular volume and maintains peripheral resistance, blood pressure levels, renal function, and renal blood flow. Renin cleaves angiotensinogen, which is produced in the liver, in angiotensin I. Angiotensin $\mathrm{I}$, an inactive decapeptide, is then converted to angiotensin II (Ang II), an active octapeptide, by the angiotensin-converting enzyme. Classically, Ang II acts on angiotensin II receptor type 1 (leading to vasoconstriction) and on angiotensin II receptor type 2 (leading to vasodilation). Under normal conditions, renin is the limiting factor in the cascade of reactions, all other components being produced in excess. Renin is produced by the juxtaglomerular cells in the renal afferent arterioles, renin release being modulated by afferent arteriolar perfusion pressure and sodium concentration in the macula densa. In contrast, Ang II controls renin release through negative feedback. Therefore, the inhibition or absence of Ang II activity leads to an overexpression of renin..$^{5,12}$

All RAS-components are expressed in human embryos. ${ }^{5}$ In humans, in whom nephrogenesis is complete before birth, ${ }^{13,14}$ renin and Ang II levels are higher in the embryonic period than in the neonatal period. The fetal RAS and the maternal RAS are independent, and it has been demonstrated that renin does not cross the placental barrier. $^{5}$ However, during the second half of pregnancy, the fetal RAS responds to maternal stimuli, including low blood flow/hypoxemia and medications such as furosemide and RAS inhibitors. ${ }^{5}$ These data constitute evidence that the RAS plays a unique role in the development of RTD.

In 1983, Allanson et al..$^{15}$ reported the case of two stillbirths, in which RTD was first described. Subsequently, just over 100 cases were reported. ${ }^{1}$ 
Studies have found topic kidneys, either normal or in which the findings were nonspecific. 1,3,4,6-8 Macroscopic examination typically reveals normal kidneys.

Histological examination reveals a lack of proximal convoluted tubules (which are diffusely distributed) and diffuse distribution of the glomeruli (which show no histological changes). Because the tubules consist of primitive cells, it is difficult to characterize them only with hematoxylin and eosin staining. Periodic acid-Schiff staining reveals a lack of proximal tubules, the brush border membrane, typical of these structures, remaining unstained..$^{1-3}$ Immunohistochemistry reveals diffusely distributed distal tubules, proximal tubules being scarce or absent. ${ }^{1,2,4}$ The renal arteries, particularly the renal interlobar arteries, are tortuous and have thickened walls. ${ }^{4,5,14}$

In the case reported here, in addition to findings that are typical of RTD, we found changes that were secondary to chronic hypotension, which is common in cases of RTD. Calvarial malformation is common, resulting in hypocalvaria and enlarged fontanelles. ${ }^{1-3,5,8,9}$ Pulmonary hypoplasia, which results from oligohydramnios, leads to refractory respiratory failure at birth. ${ }^{2-5,8}$ Persistent hypotension adds to the difficulty in treating such patients.

lleocecal valve agenesis was an interesting autopsy finding in the case reported here. To our knowledge, this finding had not been reported in the literature on RTD. We hypothesized that the ileocecal valve agenesis was due to chronic arterial hypotension. We found no intestinal perforation. However, the presence of diffuse chronic serositis, with macrophages containing greenish granules, was suggestive of phagocytosis of meconium content, constituting an indirect evidence of intestinal perforation.

Although the neonate received intensive care, respiratory failure persisted and he died at $9 \mathrm{~h}$ after delivery. Microscopic examination of the brain revealed periventricular leukomalacia, a finding that constituted further evidence of fetal distress.

\section{CONCLUSION}

Arare disorder, RTDis generallyaccompanied by oligohydramnios, which is diagnosed in the second trimester of pregnancy. The disorder should be included in the differential diagnosis of cases in which anuria and severe hypotension are usually accompanied by a normal renal ultrasound. It is extremely important to determine the etiology of RTD, particularly in suspected cases of autosomal recessive disease, in which there is a $25 \%$ chance of recurrence. Genetic counseling is therefore mandatory.

Although meconium ileus and its associated gastrointestinal obstruction are usually related to RTD, this is the first reported case of the ileocecal valve agenesis. However, new case reports are required to permit the establishment of an association of this unusual finding with RTD.

\section{REFERENCES}

1. Moldavsky M. Renal tubular dysgenesis in Israel: pathologist's experience and literature review. Isr Med Assoc J. 2009;11(1):6-10. PMid:19344005.

2. Milunsky JM, Genest DR, Milunsky A. Renal tubular dysgenesis with microcephaly. Pediatr Nephrol. 1997;11(4):494-6.PMid:9260254. http://dx.doi.org/10.1007/ s004670050325

3. Kriegsmann J, Coerdt W, Kommoss F, Beetz R, Hallermann $C$, Müntefering $H$. Renal tubular dysgenesis (RTD) - an important cause of the oligohydramnion-sequence. Report of 3 cases and review of the literature. Pathol Res Pract. 2000;196(12):861-5. PMid:11156331.

4. Lacoste M, Cai Y, Guicharnaud L, et al. Renal tubular dysgenesis, a not uncommon autosomal recessive disorder leading to oligohydramnios: Role of the ReninAngiotensin system. J Am Soc Nephrol. 2006;17(8):2253-63. PMid:16790508. http://dx.doi.org/10.1681/ASN.2005121303

5. Gubler MC, Antignac C. Renin-angiotensin system in kidney development: renal tubular dysgenesis. Kidney Int. 2010;77(5):400-6. PMid:19924102. http://dx.doi. org/10.1038/ ki.2009.423

6. John U, Benz K, Hübler A, Patzer L, Zenker M, Amann K. Oligohydramnios associated with sonographically normal kidneys. Urology. 2012;79(5):1155-7. PMid:22088568. http:// dx.doi.org/10.1016/j.urology.2011.08.058

7. Winyard P, Chitty LS. Dysplastic kidneys. Semin Fetal Neonatal Med. 2008;13(3):142-51. PMid:18065301. http:// dx.doi.org/10.1016/j.siny.2007.10.009

8. Shirakawa T, Kondoh T, Takahashi R, et al. Renal tubular dysgenesis complicated with severe cranium hypoplasia. Pediatr Int. 2004;46(1):88-90. PMid:15043673. http://dx.doi. org/10.1111/j.1442-200X.2004.01830.x 
9. Schreiber R, Gubler MC, Gribouval O, Shalev H, Landau D. Inherited renal tubular dysgenesis may not be universally fatal. Pediatr Nephrol. 2010;25(12):2531-4. PMid:20607303. http://dx.doi.org/10.1007/s00467-010-1584-0

10. Uematsu M, Sakamoto O, Ohura T, Shimizu N, Satomura $\mathrm{K}$, Tsuchiya S. A further case of renal tubular dysgenesis surviving the neonatal period. Eur J Pediatr. 2009;168(2):2079. PMid:18478260. http://dx.doi.org/10.1007/s00431-0080743-9

11. Zingg-Schenk A, Bacchetta J, Corvol P, et al. Inherited renal tubular dysgenesis: the first patients surviving the neonatal period. Eur J Pediatr. 2008;167(3):311-6. PMid:17443344. http://dx.doi.org/10.1007/s00431-007-0492-1

12. Michaud A, Bur D, Gribouval O, et al. Loss-of-function point mutations associated with renal tubular dysgenesis provide insights about renin function and cellular trafficking. Hum
Mol Genet. 2011;20(2):301-11. PMid:21036942. http://dx.doi. org/10.1093/hmg/ddq465

13. Balbi AP, Francescato HD, Marin EC, Costa RS, Coimbra TM. Roles of mitogen-activated protein kinases and angiotensin II in renal development. Braz J Med Biol Res. 2009;42(1):38- 43. PMid:19219295. http://dx.doi.org/10.1590/ S0100- 879X2009000100007

14. Chen Y, Lasaitiene D, Gabrielsson BG, et al. Neonatal losartan treatment suppresses renal expression of molecules involved in cell-cell and cell-matrix interactions. J Am Soc Nephrol. 2004;15(5):1232-43. PMid:15100363. http://dx.doi. org/10.1097/01.ASN.0000123690.75029.3F

15. Allanson JE, Pantzar JT, MacLeod PM. Possible new autosomal recessive syndrome with unusual renal histopathological changes. Am J Med Genet. 1983;16(1):57-60. PMid:6638071. http://dx.doi. org/10.1002/ ajmg.1320160110

\section{Conflict of interest: None}

Submitted on: $22^{\text {th }}$ July 2012

Accept on: $2^{\text {nd }}$ August 2012

Correspondence: Ariel Barreto Nogueira

Rua Teodoro Sampaio, 363 - apto. 601 - São Paulo/SP - Brazil CEP: 05405-000 - Phone: +55 (11) 8555-5048

E-mail: arielbarreto@gmail.com 
